\title{
Comparison of Crop Rotation for Verticillium Wilt Management and Effect on Pythium Species in Conventional and Organic Strawberry Production
}

\author{
Samuel M. C. Njoroge and Zahangir Kabir, Department of Plant Pathology, University of California, Davis, c/o \\ U.S. Agricultural Research Station, 1636 E. Alisal Street, Salinas, CA 93905; Frank N. Martin, USDA-ARS, 1636 \\ E. Alisal Street, Salinas, CA 93905; Steven T. Koike, University of California Cooperative Extension, 1432 Abbott \\ Street, Salinas, CA 93901; and Krishna V. Subbarao, Department of Plant Pathology, University of California, \\ Davis, c/o U.S. Agricultural Research Station, 1636 E. Alisal Street, Salinas, CA 93905
}

\begin{abstract}
Njoroge, S. M. C., Kabir, Z., Martin, F. N., Koike, S. T., and Subbarao, K. V. 2009. Comparison of crop rotation for Verticillium wilt management and effect on Pythium species in conventional and organic strawberry production. Plant Dis. 93:519-527.

The effects of broccoli and lettuce rotations on population densities of Verticillium dahliae and Pythium spp. in soil and on strawberry (Fragaria $\times$ ananassa) growth, yield, and Verticillium wilt were evaluated in conventional and organic production systems in California for 2 years. Under both management systems, strawberry was planted after two successive crops of broccoli or lettuce. The control treatment in the conventional field was strawberry planted in soils fumigated with methyl bromide + chloropicrin. Preplant densities of $V$. dahliae and Pythium sp. did not differ in these fields. At the end of the second broccoli crop, $V$. dahliae densities in conventional plots had declined by $44 \%$ in both years. In contrast, after the second broccoli crop, densities in organic fields decreased $47 \%$ in 2000 and $25 \%$ in 2001. In general, there were no differences in $V$. dahliae inoculum densities in organic and conventional plots following lettuce rotations. After the second vegetable production cycle, population densities of $V$. dahliae in broccoli rotated organic (24 CFU/g of soil in 2000 and $27 \mathrm{CFU} / \mathrm{g}$ of soil in 2001) or conventional (23 CFU/g of soil in 2000 and 19 CFU/g of soil in 2001) fields were significantly lower than those in lettuce rotated organic (40 CFU/g of soil in 2000 and $42 \mathrm{CFU} / \mathrm{g}$ of soil in 2001) or conventional (39 CFU/g of soil in 2000 and $35 \mathrm{CFU} / \mathrm{g}$ of soil in 2001) fields. However, crop rotation treatments had no consistent effect on the inoculum densities of Pythium spp. Canopy diameters of strawberry plants grown in rotation with broccoli were not different from those in fumigated control plots, whereas those from lettuce plots were $10 \%$ smaller. Strawberry plant nutrient analysis showed that fertilizer inputs into organic or conventional production were not responsible for the observed differences in plant size. Increases in strawberry yields were not consistent between years. Verticillium wilt incidence on strawberry was 12 to $24 \%$ lower in fields rotated with broccoli compared with fields rotated with lettuce. Wilt severity on strawberry was 22 to $36 \%$ lower in fields rotated with broccoli compared with those rotated with lettuce. The strategy of using broccoli rotation coupled with postharvest incorporation of broccoli residue continues to show promise as a tool in the management of Verticillium wilt in both conventional and organic strawberry production systems.
\end{abstract}

Strawberry (Fragaria $\times$ ananassa Duchesne) is an important crop in California, where more than $80 \%$ of total U.S. strawberry production occurs. In 2006, strawberries in California were grown on 14,575 ha with a farmgate value of US $\$ 1.2$ billion (23). Nearly all of this production occurs in fumigated soils, although in recent years, there has been an increase in organic strawberry production. In 2000, organically grown strawberry accounted for less than $1 \%$ of California strawberries (8) compared to $2.7 \%$ in 2006 (7).

Corresponding author: K. V. Subbarao

E-mail: kvsubbarao@ucdavis.edu

First two authors contributed equally to the project.

Accepted for publication 23 January 2009.

doi:10.1094/PDIS-93-5-0519

(c) 2009 The American Phytopathological Society lare are commonly isolated; 20) and binucleate Rhizoctonia spp. in AG-A, -G, or -I (21). In adjacent evaluations in fumigated and nonfumigated field plots, this disease caused yield losses ranging from 15 to $>50 \%$ depending on the cultivar grown (22). Unfortunately, there are no foliar symptoms diagnostic of this disease complex other than a reduction in growth of the plant (which can also be caused by other soilborne pathogens).

Broad-spectrum fumigation with methyl bromide + chloropicrin to eliminate viable microsclerotia of $V$. dahliae has been the mainstay of conventional strawberry production systems in California (43). With the elimination of methyl bromide as a soil fumigant, Verticillium wilt will likely reemerge as a major threat in strawberry production unless effective alternative control measures are implemented (35). Without an effective alternative to methyl bromide fumigation, crop losses have been projected to be nearly 20 to $30 \%$ of the estimated farmgate value of the crop $(8,37)$. Research aimed at finding alternative chemicals to methyl bromide is ongoing, and some candidate chemicals have been identified $(1,2,11,17)$; however, these chemical alternatives will be subjected to increasing review and regulation, potentially making them unavailable in the longterm (12). Therefore, research to identify and evaluate effective nonchemical alternatives for moderating the impact of soilborne diseases is needed. These alternative disease management strategies also will be potentially useful in organic strawberry fields, where Verticillium wilt is already a major problem at some locations.

Currently, Verticillium wilt resistant commercial strawberry cultivars are unavailable. An integrative approach to Verticillium wilt disease management in nonfumigated and organic strawberry production may involve the use of crop rotation to reduce microsclerotia populations in the soil. Owing to the wide host range of the pathogen (4) and the longevity of microsclerotia in soil (26), crop rotation was thought to be ineffective against Verticillium wilt (26). Since the mid-1990s, rotations with broccoli (Brassica oleracea Italica group) have repeatedly been shown to reduce Verticillium wilt on cauliflower $(29,32,34,45)$, and more recently on straw- 
berry grown in conventional soils (35). Broccoli rotations for managing Verticillium wilt on strawberries are expected to be equally successful in both conventional and organic strawberry production systems (35), but this has not been demonstrated. Even though broccoli rotations have not been confirmed to be effective in organic fields, organic strawberry growers in California are currently utilizing broccoli as one of the rotation crops.

Lettuce (Lactuca sativa L.) is an important crop in the coastal valleys of California that also is susceptible to Verticillium wilt (31). Rotating strawberries with lettuce may potentially increase Verticillium wilt incidence on strawberry because of the large numbers of microsclerotia that can form on infected lettuce plants $(35,38)$, and also because isolates of $V$. dahliae from lettuce are cross pathogenic to strawberry (4). However, the current practice for conventional lettuce production fields that develop Verticillium wilt is to fumigate, plant strawberries, and follow with lettuce crops to exploit the beneficial effects of postfumigation on production. Unfortunately, this option is not available for organic growers, and therefore, lettuce grown in rotation with strawberry may increase Verticillium wilt on the latter in organic production systems. Current organic strawberry production schemes in California involve fallowing after strawberry or rotating with lettuce.

Very few comparative studies of disease development under organic and conventional farming systems have been published. One study conducted in California (27) compared the incidence of Verticillium spp. recovered from strawberry roots for 3 years in a field that was converted to organic production to that in conventional strawberry fields. Results were not consistent because at the end of the study, population densities of Verticillium spp. in the organic fields either were significantly lower or not significantly different from densities in the conventional soils.

Ultimately, strawberry growers are interested in maximizing fruit yield. Inherent differences in strawberry yield between organic and conventional production systems may be caused by the differences in inputs such as fertilizers. Such differences may also influence plant size measured as canopy area or density, which can be correlated with strawberry yield (F. Martin, unpublished). Although strawberry plant canopy diameter was evaluated in a previous study focusing on conventional production (35), it was not related to the nutrient status of the plants. The objectives of this study were to compare the effects of broccoli or lettuce rotations in organic and conventional production systems on (i) the survival of $V$. dahliae and Pythium spp., (ii) incidence and severity of Verticillium wilt of strawberry, and (iii) plant growth, nutrient content, and strawberry yield.

\section{MATERIALS AND METHODS}

Field site. The organic and conventional fields were located $200 \mathrm{~m}$ apart at the Monterey Bay Academy in Watsonville, CA. The organic fields had been certified organic for the previous 4 years, and strawberry had been grown during the past 15 years. The soil type was Elder sandy loam (coarse-loamy, mixed, thermic, $\mathrm{Cu}$ mulic Haploxeroll) with $62 \%$ sand, $26 \%$ silt, $\mathrm{pH} 6.1$, and organic matter content of $0.6 \%$. All experiments were managed by the same commercial grower using standard practices for coastal California vegetable and strawberry production.

Conventional plots. Three treatments set up in a randomized complete block and replicated four times were evaluated: (i) two successive broccoli (cv. Marathon) crops followed by strawberry (cvs. Aromas in 2001 and Camarosa in 2002), (ii) two successive lettuce (cv. Salinas) crops followed by strawberry, and (iii) strawberry planted after fumigation with methyl bromide and chloropicrin (67:33, applied at $450 \mathrm{~kg} / \mathrm{ha})(\mathrm{Mb}+\mathrm{Pic})$. Six beds, $9 \mathrm{~m}$ long and $1.3 \mathrm{~m}$ wide, were formed in each replication, and $450 \mathrm{~kg} / \mathrm{ha}$ of $15 \mathrm{~N}-15 \mathrm{P}-15 \mathrm{~K}$ slow release synthetic fertilizer was applied. In February 2000 and 2001, three rows of 4- to 5-week-old broccoli or lettuce were transplanted into each bed. Two outer rows of broccoli and lettuce were spaced 15 and 25 to $30 \mathrm{~cm}$ apart within rows, respectively, and the spacing was halved for the middle row. This was done to maximize the biomass produced per unit area. Two side dressings of slow release synthetic fertilizer $15 \mathrm{~N}-15 \mathrm{P}-15 \mathrm{~K}$ were applied at $672 \mathrm{~kg} / \mathrm{ha}$ on 15 February and 12 March 2000, and on 17 February and 16 March 2001. All marketable lettuce and broccoli were harvested at maturity on 5 April 2000 and 8 April 2001. The remaining residues were flail-shredded, and $48 \mathrm{~h}$ later incorporated into the soil using a rototiller. Three to four weeks after incorporation, beds were formed and fertilized as described earlier. In May 2000 and 2001 , the second crops of broccoli or lettuce were transplanted as previously described and side-dressed 2 weeks later with a slow release fertilizer $(18 \mathrm{~N}-8 \mathrm{P}-13 \mathrm{~K})$ at $672 \mathrm{~kg} / \mathrm{ha}$. At maturity, all marketable lettuce and broccoli were harvested 17 July 2000 and 20 July 2001. Residues were mowed as described earlier, and beds were prepared for the strawberry crop. In November 2000, strawberry (cv. Aromas) was transplanted, spaced $31 \mathrm{~cm}$ apart, into two rows on raised beds $1.3 \mathrm{~m}$ wide. In 2001, a repeat of this experiment was initiated in an adjacent section of the field that was left fallow in 2000. In the repeat experiment, a different strawberry cv. Camarosa was transplanted in November 2001. In the fumigation treatment, $\mathrm{Mb}+\mathrm{Pic}$ (67:33) was applied by a commercial applicator at a depth of 15 to $25 \mathrm{~cm}$ to the center of the beds, through hollow shanks at the rate of
$450 \mathrm{~kg} / \mathrm{ha}$, on 27 September 2000 and 2 October 2001. Immediately after application of the fumigants, the beds were covered with a high-density brown polyethylene tarp. In both years, strawberry was transplanted in November and managed by the grower in accordance with local commercial practices.

Organic plots. The organic production was managed using nonsynthetic inputs in accordance with the California Health and Safety Code Section 2659.11-17 and the California Certified Organic farmer's guidelines and enforcement provisions. Two treatments in a randomized complete block replicated four times were evaluated: (i) two successive broccoli (cv. Marathon) crops followed by strawberry (cvs. Aromas in 2001 and Camarosa in 2002), and (ii) two successive lettuce (cv. Salinas) crops followed by strawberry. Planting beds were formed, and $672 \mathrm{~kg} / \mathrm{ha}$ of blood meal $12 \mathrm{~N}-0 \mathrm{P}-0 \mathrm{~K}$ was applied. Broccoli and lettuce were transplanted as described for the conventional field. For vegetable crops, fertilizer was applied as two side dressings of blood meal with $15 \mathrm{~N}-0 \mathrm{P}-0 \mathrm{~K}$ at 11 to $22 \mathrm{~kg} / \mathrm{ha}$ on 17 February and 14 March 2000, and 19 February and 18 March 2001. At maturity, broccoli or lettuce crops were harvested, their residues incorporated, and beds reshaped for strawberry production as described for the conventional field. At the time of bed preparation, a total of $1,344 \mathrm{~kg} / \mathrm{ha}$ blood meal was applied and mixed into the bed profile. To provide supplemental fertilizer during the growing season, the liquid organic fertilizer Phytamin 800 (California Organic Fertilizers Inc., Hartford, CA) was applied in the irrigation water at 93 liters/ha with a drip system every 2 weeks. The Phytamin 800 is derived from seabird guano, fish solubles, and potassium sulfate $(6 \mathrm{~N}-1 \mathrm{P}-1 \mathrm{~K})$ with $5.0 \%$ water-soluble organic nitrogen and $1.0 \%$ water insoluble organic nitrogen, $1 \%$ available phosphoric acid $\left(\mathrm{P}_{2} \mathrm{O}_{5}\right)$, and $1 \%$ available potash $\left(\mathrm{K}_{2} \mathrm{O}\right)$.

$V$. dahliae inoculum density. To estimate the inoculum densities of $V$. dahliae, soil samples were taken from 0 to $10 \mathrm{~cm}$ depth approximately 1 week after planting broccoli or lettuce and then at monthly intervals until the end of the strawberry season. At each time, we sampled soil from 10 sites per replication and bulked the soils collected within the replication. After air-drying the soil for 4 weeks in the greenhouse, the modified Anderson sampler technique (6) was used to plate the soil on the modified NP-10 medium (16). The plates were incubated for 3 weeks in the dark at room temperature $\left(23\right.$ to $\left.25^{\circ} \mathrm{C}\right)$, the agar surface then was washed under a gentle stream of tap water, and microsclerotial colonies were counted under a stereomicroscope $(\times 10)$. The colonies were expressed as microsclerotia per gram of dry soil. 
Pythium inoculum density. Densities of Pythium spp. were estimated from soil samples collected as described above for $V$. dahliae. To determine the number of colony forming units of Pythium, $1 \mathrm{~g}$ of airdried soil was added to $10-\mathrm{ml}$ sterilized water blanks (triplicate tubes for each sample), vortexed to mix the soil, and 500 $\mu \mathrm{l}$ of this soil solution was distributed evenly over a petri dish containing a semiselective Pythium medium (five plates per tube). The medium consisted of corn meal agar (17 g/liter, BBL, Kansas City, MO) amended immediately after autoclaving with $0.1 \%$ Tween 20 followed by pimaricin (10 $\mathrm{mg} / \mathrm{liter})$, ampicillin (250 $\mathrm{mg} /$ liter), rifampicin (10 $\mathrm{mg} /$ liter), rose bengal (50 mg/liter), and Benomyl 50WP
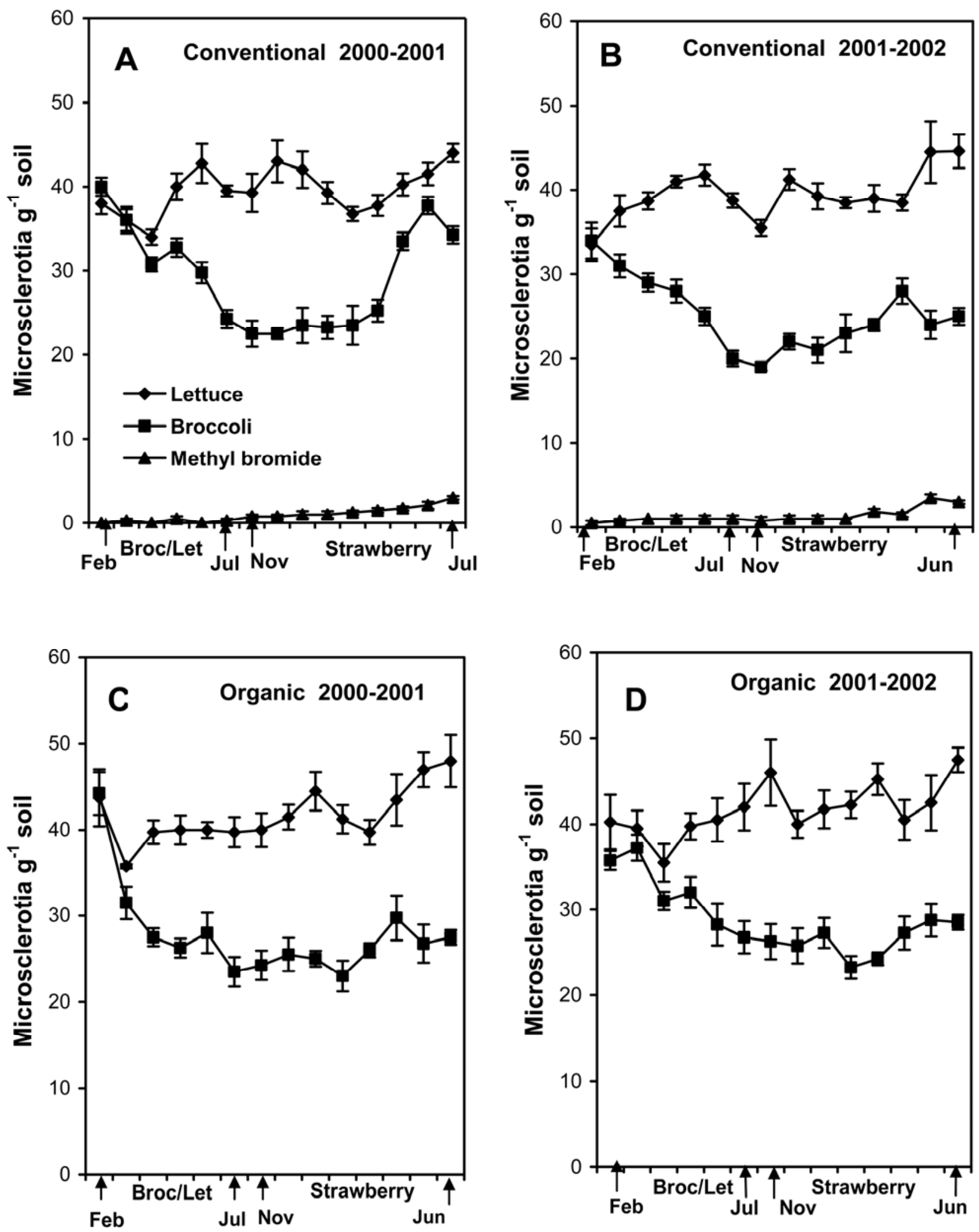

Fig. 1. Inoculum densities of Verticillium dahliae assayed at monthly intervals in conventional (A, 2000-2001, B, 2001-2002) or organic (C, 2000-2001, D, 2001-2002) fields during broccoli/lettuce and strawberry rotations. In 2000 and 2001, the first crops of broccoli and lettuce were planted in February and the second crops in May. In both years, strawberry was planted in November. Vertical bars represent one standard error of the mean. 
(20 mg/liter, DuPont, Wilmington, DE) after the medium had cooled to $50^{\circ} \mathrm{C}(28)$. After $24 \mathrm{~h}$ incubation at $25^{\circ} \mathrm{C}$, the surfaces of the plates were washed free of soil under a gentle stream of water and the number of colonies counted. Plates were placed back into the incubator and subsequent counts made again after an additional $24 \mathrm{~h}$. The total colony counts were expressed as colony forming units per gram (CFU/g) of dry soil, and the data presented are the mean of the three replicates. Prior investigations at these sites revealed that $P$. ultimum was the most commonly encountered species, but other species such as $P$. irregulare were recovered as well (20).

Verticillium wilt incidence and severity assessments. To monitor disease pro- gress, 20 plants per plot were visually rated for Verticillium wilt severity every other week from May through August (Julian days 149, 168, 192, 205, 214, and 227 in 2001 and 145, 168, 184, 205, 217, and 227 in 2002) based on a scale of 1 to 8 , where $1=$ no symptoms; 2 = moderately stunted; 3 = moderately stunted, slight rosette of dead leaves; $4=$ moderately stunted, moderate rosette; $5=$ significantly stunted, slight rosette; $6=$ significantly stunted, moderate rosette; $7=$ significantly stunted, significant rosette; $8=$ dead plant. Disease incidence was recorded on 20 plants from the center portion of the treatment bed that had been flagged out.

Strawberry plant growth, nutrient analyses, and yield. To determine the relative effects of different rotation treatments on strawberry plant growth during establishment, the canopy diameter of the same 20 plants used for assessing disease incidence was monitored monthly until runners formed. Measurements of each plant were made in the east-west and north-south directions, and averaged. $\mathrm{Nu}$ trient levels of the plants were determined from 10 plants per replication, collected on 23 April and 12 May 2001, and 27 April and 15 May 2002. These plants were dried at $60^{\circ} \mathrm{C}$ and then sent to University of California's Agricultural and Natural Resources Laboratory in Davis for total nitrogen, phosphorus, and potassium analyses. Yield data were collected from the same 20 plants (used for disease and plant

Table 1. Mean inoculum densities of Verticillium dahliae at the start of the study and at the end of broccoli (Broc) or lettuce (Let) and end of strawberry (Strawb) production and probabilities associated with contrasts between treatment effects on populations of $V$. dahliae in organic (Org) or conventional (Conv) production systems

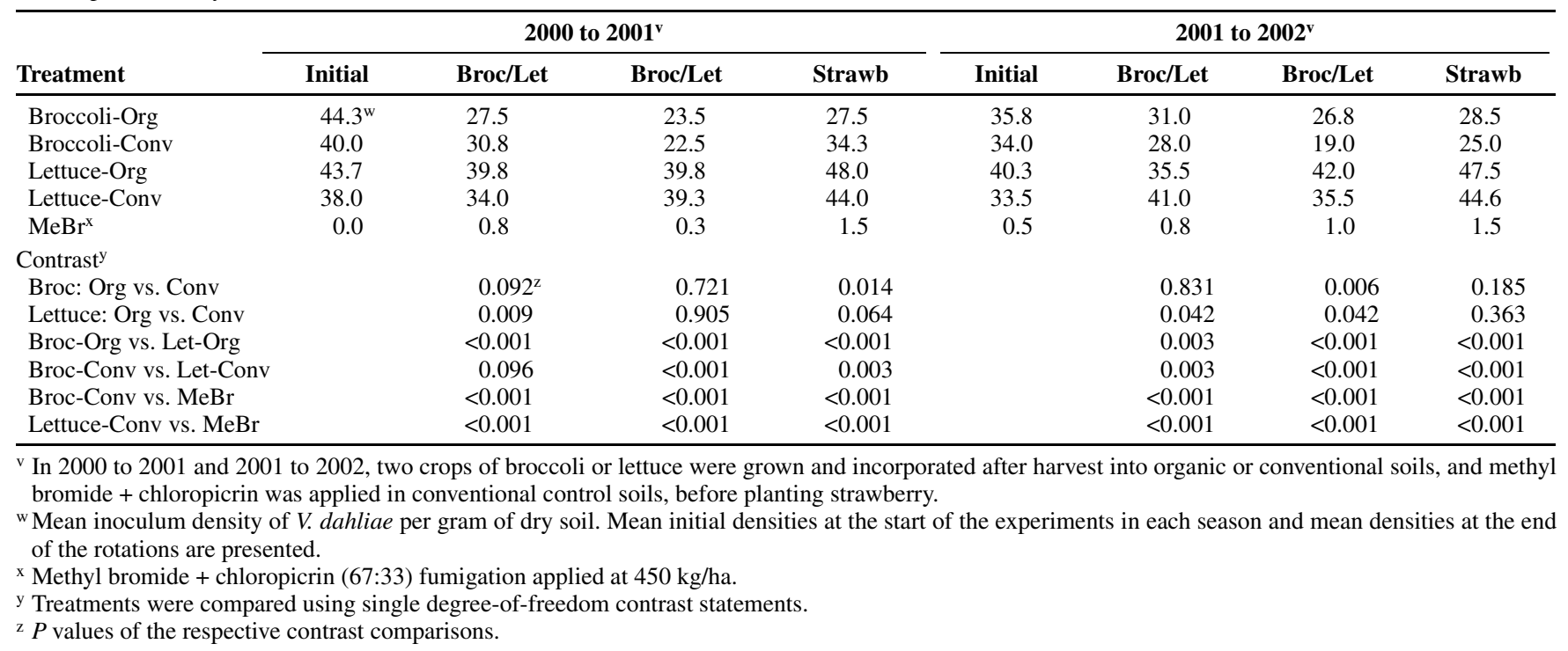

Table 2. Effect of crop rotations in organic (Org) or conventional (Conv) fields on disease incidence and severity of Verticillium wilt and yield on strawberry

\begin{tabular}{|c|c|c|c|c|c|c|}
\hline \multirow[b]{3}{*}{ Treatment $^{v}$} & \multicolumn{3}{|c|}{$2001^{u}$} & \multicolumn{3}{|c|}{$2002^{u}$} \\
\hline & \multicolumn{2}{|c|}{ Disease } & \multirow[b]{2}{*}{ Yield $^{\mathrm{w}}$} & \multicolumn{2}{|c|}{ Disease } & \multirow[b]{2}{*}{ Yield } \\
\hline & $\%$ Incidence $^{\mathrm{v}}$ & Severity $^{v}$ & & $\%$ Incidence & Severity & \\
\hline Broccoli (Broc)-Org & 20.3 & 120 & 0.631 & 11.8 & 116 & 0.444 \\
\hline Broccoli-Conv & 22.8 & 131 & 0.987 & 56.8 & 216 & 0.622 \\
\hline Lettuce (Let)-Org & 37.2 & 154 & 0.527 & 31.3 & 170 & 0.440 \\
\hline Lettuce-Conv & 47.2 & 204 & 0.863 & 68.7 & 276 & 0.293 \\
\hline $\mathrm{MeBr}^{\mathrm{x}}$ & 15.3 & 114 & 1.270 & 24.4 & 144 & 0.543 \\
\hline \multicolumn{7}{|l|}{ Contrast $\mathrm{y}^{\mathrm{y}}$} \\
\hline Broccoli: Org vs. Conv & $0.446^{\mathrm{z}}$ & 0.084 & $<0.001$ & $<0.001$ & $<0.001$ & 0.001 \\
\hline Lettuce: Org vs. Conv & 0.003 & $<0.001$ & $<0.001$ & 0.003 & $<0.001$ & 0.004 \\
\hline Broc-Org vs. Let-Org & $<0.001$ & $<0.001$ & 0.014 & $<0.001$ & $<0.001$ & 0.916 \\
\hline Broc-Conv vs. Let-Conv & $<0.001$ & $<0.001$ & 0.095 & $<0.001$ & $<0.001$ & 0.002 \\
\hline Broc-Conv vs. MeBr & 0.023 & 0.011 & 0.007 & $<0.001$ & $<0.001$ & 0.269 \\
\hline Let-Conv vs. MeBr & $<0.001$ & $<0.001$ & 0.001 & $<0.001$ & $<0.001$ & 0.008 \\
\hline
\end{tabular}

u In 2000 to 2001 and 2001 to 2002, two crops of broccoli or lettuce were grown and incorporated after harvest into organic or conventional fields, and methyl bromide + chloropicrin was applied in conventional control soils, before transplanting strawberry.

${ }^{v}$ Plants were examined and rated for Verticillium wilt incidence and severity from May to August (Julian days 149, 168, 192, 205, 214, and 227 in 2001 and 145, 168, 184, 205, 217, and 227 in 2002). Final disease incidence is presented. For wilt severity, areas under disease progress curves for each replication were calculated and averaged within treatments.

${ }^{\text {w }}$ Total marketable yield $(\mathrm{kg})$ per plant.

${ }^{x}$ Methyl bromide + chloropicrin (67:33) fumigation applied at $450 \mathrm{~kg} / \mathrm{ha}$.

y Treatments were compared using single degree-of-freedom contrast statements.

${ }^{\mathrm{z}} P$ values of the respective contrast comparisons. 
growth assessments) with both marketable and nonmarketable fruit yield data collected in each treatment replication by a specially trained commercial picking crew. Fruit yield data were expressed as grams per plant.

Statistical analysis. Prior to analysis, $V$. dahliae population density, disease incidence, canopy diameter, and yield data sets were checked for normality (PROC Univariate, SAS version 9.1, Cary, NC), and Hartley's test for equality of variance was conducted (18). Repeated measures analysis (PROC Mixed, SAS version 9.1) was done, for each vegetable rotation and strawberry production period, to test the effects of the treatments and time on densities of $V$. dahliae. Autoregressive covariance matrix was used in the analysis. Standard errors of the mean were calculated for $V$. dahliae inoculum densities. Using single degree-of-freedom contrasts, comparisons of mean $V$. dahliae densities at the start of the rotations and at the end of each broccoli or lettuce rotation, and strawberry production, within and across organic or conventional fields were done. Single degree-of-freedom contrasts were also used to compare disease incidence and yield. For disease severity, areas under disease progress curves for each replication were calculated and averaged within treatments, and then contrasts were made between treatments. Strawberry plant nutrient data were analyzed by year, and were compared using Fisher's protected least significant difference $(P \leq 0.05)$ and single degree-offreedom contrasts.

\section{RESULTS}

Initial $V$. dahliae densities and methyl bromide treatment comparison. In both years, initial densities of $V$. dahliae microsclerotia (34 to $44 \mathrm{CFU} / \mathrm{g}$ of soil) prior to establishing the broccoli and lettuce rotation treatments did not differ significantly $(P>0.05)$ (Fig. 1). In both years during broccoli and lettuce cropping, $V$. dahliae densities in methyl bromide-treated soils $(<2 \mathrm{CFU} / \mathrm{g}$ of soil) remained significantly $(P<0.001)$ lower than in broccoli-rotated (19 to $31 \mathrm{CFU/g}$ of soil) or lettuce-rotated (34 to $42 \mathrm{CFU} / \mathrm{g}$ of soil) soils in either conventionally or organically managed system (Fig. 1, Table 1).

Effects of vegetable rotations on $\boldsymbol{V}$. dahliae densities. In general, densities of $V$. dahliae did not differ between organic and conventional plots after cropping to broccoli (Table 1). At the end of the second broccoli crop, $V$. dahliae densities in conventional plots had declined by $44 \%$ in both 2000 and 2001. In contrast, after the second broccoli crop, densities in organic fields decreased $47 \%$ in 2000 and $25 \%$ in 2001. In general, densities of $V$. dahliae were not different between organic and conventional plots after cropping to lettuce (Table 1). By the end of the second broccoli and lettuce crops (July) within organic or conventional fields, densities of $V$. dahliae were significantly lower in soils cropped to broccoli than in soils cropped with lettuce (Fig. 1, Table 1).

At the time strawberries were planted, $V$. dahliae densities in broccoli-rotated conventional and organic plots were significantly lower than the corresponding initial densities (Fig. 1). In contrast, $V$. dahliae densities in organic and conventional fields were not significantly different from initial densities in lettuce-rotated plots (Fig. 1).

$V$. dahliae densities during strawberry production. $V$. dahliae densities remained significantly lower in plots rotated with broccoli relative to plots rotated with lettuce (Fig. 1, Table 1). In both years, $V$. dahliae densities were significantly $(P \leq$ 0.02 ) higher during strawberry production following lettuce rotations in organic fields (43.1 CFU/g of soil in 2001 and 42.8 CFU/g of soil in 2002) compared with those in the corresponding conventional fields (40.4 CFU/g of soil in 2001 and 39.5 CFU/g of soil in 2002).

The effect of rotation treatments on Pythium inoculum densities. Inoculum densities of Pythium spp. in the rotation treatments ranged from 8 to $368 \mathrm{CFU} / \mathrm{g}$ of soil compared to less than $1 \mathrm{CFU} / \mathrm{g}$ of soil for the $\mathrm{Mb}+$ Pic fumigated control in the conventional plots. Consistent differences between years in inoculum densities of Pythium spp., in response to rotation treatments or conventional compared to organic production practices, was not observed largely due to the level of variability observed among the replicates for each treatment (data not shown).

Verticillium wilt incidence and severity. In both 2001 and 2002, disease incidence and severity were significantly lower in broccoli-rotated organic or conventional fields compared with those in lettuce rotations (Table 2). In 2001, disease incidence or severity was not significantly different between broccoli-rotated organic or conventional fields; but in 2002, both values were significantly higher in broccolirotated conventional fields (Table 2). In both years, disease incidence and severity were significantly higher in conventional plots with lettuce rotation compared with the organically managed plots of lettuce rotation (Table 2). In both years, disease incidence was significantly lower in plots
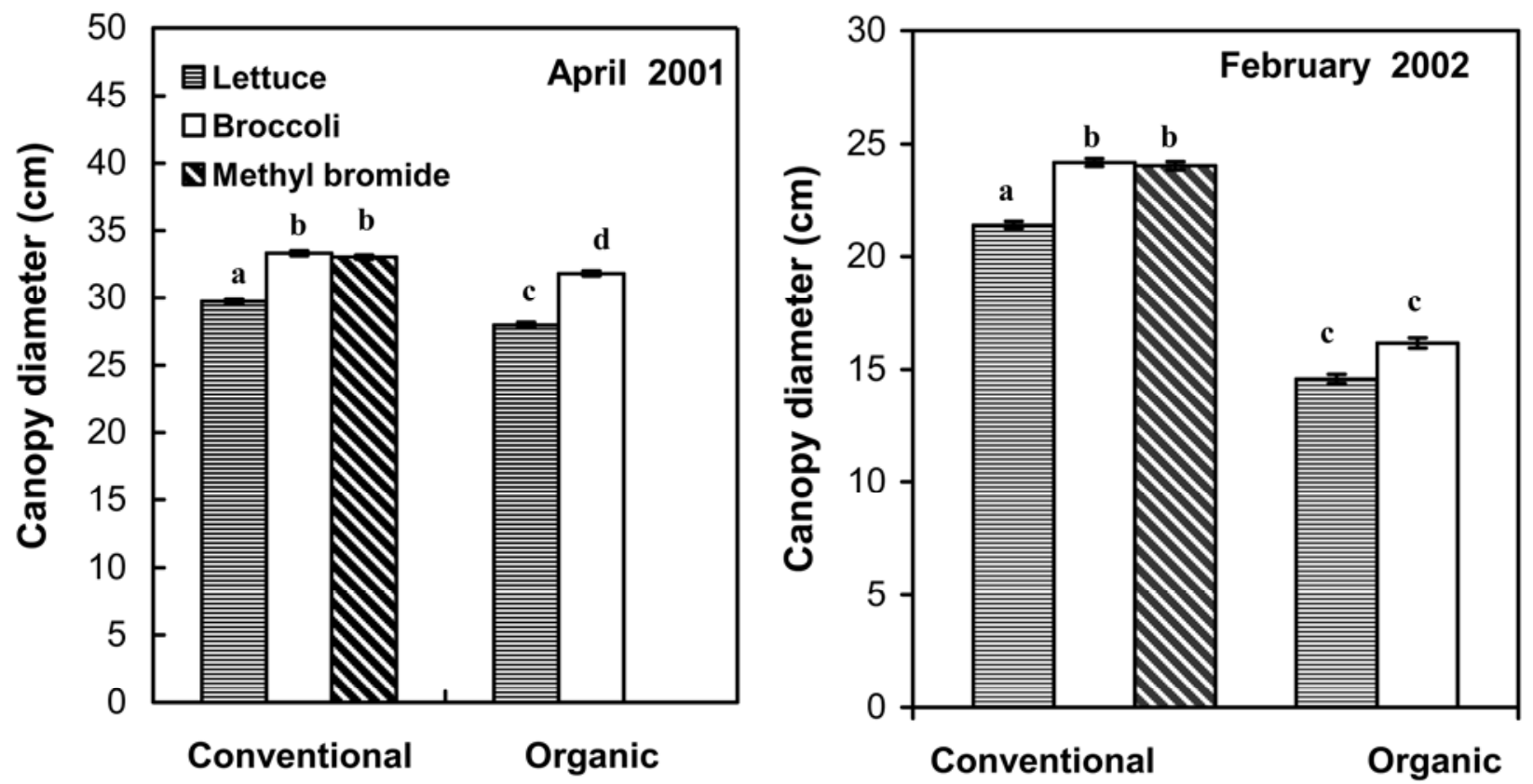

Fig. 2. Canopies of strawberry measured in April 2001 and February 2002. Different letters above the bars indicate significant differences according to LSD $P \leq 0.05$, and vertical bars represent one standard error of the mean. 
fumigated with $\mathrm{Mb}+$ Pic compared with those from lettuce- or broccoli-rotated conventionally managed plots (Table 2 ).

Effect on strawberry growth, yield, and nutrient content. In both years, there were no significant differences between the canopy diameters of strawberry plants grown in $\mathrm{Mb}+\mathrm{Pic}$ fumigated and broccoli rotation treatments (Fig. 2). Strawberry canopies were significantly smaller for plants grown in rotation with lettuce compared to those grown in broccoli or fumigated plots (Fig. 2). Strawberry yields were significantly higher in conventional fields compared to those in organic fields (Table 2). Yield differences between broccoli and lettuce rotations were not consistent in organically managed plots, with significant differences observed in 2001 but not in 2002 (Fig. 3). In contrast, straw- berry yields were significantly higher in broccoli-rotated conventional plots compared with those in lettuce rotation in 2002 (Fig. 3, Table 2).

In general, interaction effects of sampling time $\times$ nutrient content were significant $(P \leq 0.01)$ within both years. Significant differences between certain elements in the foliage of strawberry plants from different treatments were
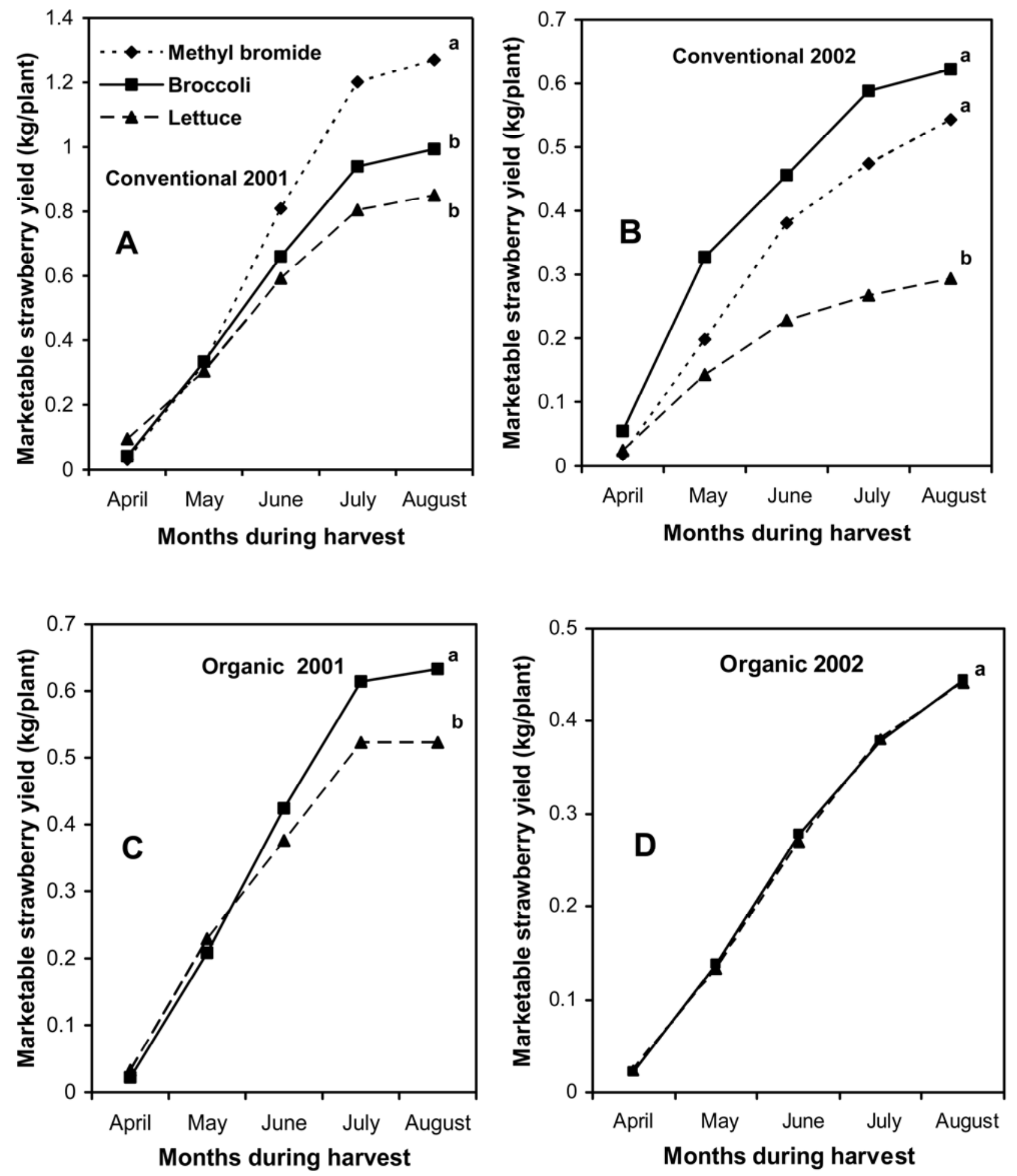

Fig. 3. Cumulative yield of strawberry plants grown in conventional (A, 2001, B, 2002) or organic (C, 2001, D, 2002) fields after crop rotation with broccoli, lettuce, or fumigation with methyl bromide + chloropicrin $(67: 33)$ at $450 \mathrm{~kg} / \mathrm{ha}$. Different letters on the lines indicate significant differences according to LSD $P \leq 0.05$. 
observed, but these differences were inconsistent both between years and sampling times (Table 3 ).

\section{DISCUSSION}

Previous studies conducted under nonfumigated conventional farming systems have demonstrated the effectiveness of rotation with broccoli in the management of Verticillium wilt of cauliflower $(32,34,45)$, potato $(25)$, and more recently strawberry (35). Of greater interest in this study was whether Verticillium wilt disease intensity would be similarly affected in organic production systems following broccoli rotations. Results obtained in this study clearly demonstrated that rotations with broccoli were equally effective in both conventional and organic productions systems and are therefore useful in managing Verticillium wilt on strawberries and perhaps on other susceptible crops.

Unlike in 2001, disease incidence and severity on strawberries in 2002 were higher despite similar microsclerotial densities in conventionally managed broccoli rotation plots compared with organically managed broccoli rotation plots. Over time, root disease levels in established organic fields diminish compared to conventionally managed soils (39). Even though data from two growing seasons were insufficient to support this conclusion in our study, the change in strawberry cultivars from Aromas in 2000 to Camarosa in 2001, which is more susceptible to Verticillium wilt than Aromas (13), may have allowed for better detection of disease suppression in the organic system.

In coastal California, conventional strawberries are planted following fumigation with $\mathrm{Mb}+\mathrm{Pic}$ or alternative fumigants. In contrast, lettuce crops are routinely produced in nonfumigated soils. However, in recent years, Verticillium wilt on lettuce has become a major threat to lettuce crops in this area and microsclerotial densities of up to 2,500 per gram of dry soil have been documented in these fields (33). Since many crops grown in rotation with lettuce are also hosts for $V$. dahliae and very few crops can be economically produced at such high inoculum densities, fumigation remains the only option to recover these fields for economic crop production. Since regular fumigation is too expensive for producing lettuce, vegetable growers often seek to plant lettuce on ground that in the previous season was fumigated and subsequently planted to strawberry; lettuce crop therefore benefits from residual fumigation effects from the previous crop. Thus, lettuce-strawberrylettuce rotations are common in conventional production systems. In contrast, organic production is antithetical to fumigation, and thus rotational crops for strawberries have to be selected carefully. Since populations of $V$. dahliae in soil typically increase following lettuce crops (35), it is not an ideal rotation crop for organic strawberry production in $V$. dahliaeinfested soils. Even though populations of $V$. dahliae did not significantly increase following two lettuce crops prior to strawberry planting, $V$. dahliae microsclerotial densities were nonetheless higher than in plots rotated with broccoli. Thus, soil tests to detect the presence of $V$. dahliae and levels of pathogen microsclerotia should be employed before deciding on lettuce as a crop to rotate with strawberries in organic production systems. In both systems, however, broccoli crops not only reduced the existing numbers of microsclerotia but also did not augment microsclerotia in the soil (45).

Interestingly, the incidence and severity of Verticillium wilt on strawberry were higher in the conventionally managed lettuce rotation plots compared with organically managed rotation plots even though $V$. dahliae microsclerotial densities at the time of strawberry production were similar in both fields. As previously discussed for disease intensities in broccoli rotations, disease suppression in organic soils may be the reason for lower disease in organic fields in the second year, coupled with the change in cultivars grown in 2001 compared to 2000. In other studies, lower disease incidence in organic compared to conventional fields may occur because $V$. dahliae densities decreased under organic production $(27,39)$, but no such conclusion can be drawn from this study. Disease suppression due to an increase in antagonistic microflora in organic soils may have played a role in reducing disease incidence, but this was not verified.

As reported by Subbarao et al. (35) in a conventionally managed strawberry production system, Verticillium wilt on strawberry grown in broccoli-rotated soils was lower than that in lettuce-rotated soils. Not surprisingly, disease levels in fumigated soils were lower compared with rotation treatments in 2001, but not in 2002. One possible reason for this was an incomplete bed fumigation, which in this particular location can lead to poor control of Verticillium wilt (F. Martin, unpublished). Another potential explanation is that even low densities of $V$. dahliae may incite high wilt incidences on strawberries. Harris and Yang (15) reported that on very susceptible cultivars, 3.8 CFU/g of soil incited $29 \%$ wilt. In our study, densities of $V$. dahliae in fumigated soils were lower than $2 \mathrm{CFU} / \mathrm{g}$ of soil, and wilt incidences in these soils were 15.3 and $24.4 \%$ in 2001 and 2002, respectively. Although high, the amount of wilt in fumigated soils therefore was not surprising.

As was observed in a previous study (35), rotation treatments had no consistent effect on populations of total Pythium. Inconsistent results from such studies are not uncommon. Amending soil with Brassica spp. increased populations of Pythium spp., fluorescent pseudomonads, and Fusarium oxysporum $(10,24,30)$, and in

Table 3. Analyses of nutrient content of strawberry plants grown in organic (Org) or conventional (Conv) fields following rotation with two plantings of broccoli (Broc) or lettuce (Let), and in methyl bromide $(\mathrm{MeBr})$ treated soils

\begin{tabular}{|c|c|c|c|c|c|c|}
\hline \multirow[b]{2}{*}{ Treatment } & \multicolumn{3}{|c|}{ April ${ }^{\mathbf{v}}$} & \multicolumn{3}{|c|}{ May } \\
\hline & $\mathbf{N}(\%)$ & $\mathbf{P}(\%)$ & $\mathbf{K}(\%)$ & $\mathbf{N}(\%)$ & $\mathbf{P}(\%)$ & $\mathbf{K}(\%)$ \\
\hline \multicolumn{7}{|l|}{2001} \\
\hline Broc-Conv & 2.76 & 0.49 & 2.08 & 1.95 & 0.32 & 1.87 \\
\hline Let-Conv & 2.79 & 0.48 & 2.22 & 1.82 & 0.29 & 1.67 \\
\hline $\mathrm{MeBr}^{\mathrm{w}}$ & 2.78 & 0.57 & 2.14 & 1.95 & 0.31 & 1.60 \\
\hline Broc-Org & 2.70 & 0.43 & 2.07 & 2.46 & 0.29 & 1.73 \\
\hline Let-Org & 2.67 & 0.43 & 2.00 & 1.88 & 0.27 & 1.45 \\
\hline LSD Conv $v^{x}$ & 0.27 & 0.05 & 0.12 & 0.18 & 0.04 & 0.07 \\
\hline $\operatorname{LSD} \operatorname{Org}^{\mathrm{x}}$ & 0.17 & 0.08 & 0.13 & 0.31 & 0.05 & 0.62 \\
\hline \multicolumn{7}{|l|}{ Contrast $\mathrm{t}^{\mathrm{y}}$} \\
\hline Broc: Org vs. Conv & n.s. ${ }^{\mathrm{z}}$ & n.s. & n.s. & $0.001^{\mathrm{z}}$ & n.s. & n.s. \\
\hline Let: Org vs. Conv & n.s. & n.s. & 0.001 & n.s. & n.s. & n.s. \\
\hline \multicolumn{7}{|l|}{2002} \\
\hline Broc-Conv & 2.43 & 0.30 & 1.83 & 2.13 & 0.30 & 1.60 \\
\hline Let-Conv & 2.14 & 0.26 & 1.43 & 1.68 & 0.29 & 1.02 \\
\hline $\mathrm{MeBr}$ & 2.36 & 0.29 & 1.61 & 1.76 & 0.29 & 1.19 \\
\hline Broc-Org & 2.55 & 0.29 & 1.73 & 2.01 & 0.29 & 1.47 \\
\hline Let-Org & 2.45 & 0.27 & 1.66 & 1.60 & 0.23 & 0.95 \\
\hline LSD Conv & 0.19 & 0.03 & 0.18 & 0.13 & 0.07 & 0.14 \\
\hline LSD Org & 0.43 & 0.05 & 0.19 & 0.16 & 0.05 & 0.08 \\
\hline \multicolumn{7}{|l|}{ Contrast } \\
\hline Broc: Org vs. Conv & n.s. & n.s. & n.s. & n.s. & n.s. & n.s. \\
\hline Let: Org vs. Conv & 0.01 & n.s. & 0.01 & n.s. & 0.001 & n.s. \\
\hline
\end{tabular}

${ }^{\mathrm{v}}$ In both years, 10 strawberry plants were sampled from each replication in April and May, dried at $70^{\circ} \mathrm{C}$, and analyzed for nitrogen, phosphorus, and potassium content.

${ }^{w}$ Methyl bromide + chloropicrin (67:33) fumigation applied at $450 \mathrm{~kg} / \mathrm{ha}$.

${ }^{\mathrm{x}}$ Least significant difference $(P=0.05)$ for comparisons within conventional or organic treatments.

${ }^{y}$ Contrasts between treatments in organic and conventional production systems.

z Nonsignificant $(P>0.05)$ and significant $P$ value. 
contrast did not significantly reduce inocula of Fusarium spp., R. solani, and V. dahliae $(5,46)$ or suppress populations of fluorescent pseudomonads (10). Reasons for the mixed results are not well understood but may be related to soil type, soil temperature at time of amendment $(14,32)$, amount and size of plant tissue incorporated $(9,25)$, successfully creating reducing conditions after amending by applying polyethylene mulch (5), or incorporating dry or fresh plant material (32).

Because fertilizer inputs into organic and conventional production systems may be unequal and thus affect plant growth and yield, we analyzed strawberry plant nutrient content and measured canopy diameters. Plant nutrient data showed that fertilizer type applied did not alter the levels of N-P-K in either organic or conventional production systems, and the levels of N-P-K in the plants were normal (M. Bolda, personal communication). Even though strawberry canopies were statistically smaller in lettuce-rotated plots than in broccoli-rotated plots, differences were not consistent between years. As expected, strawberry yields generally were higher in fumigated soils compared to those from broccoli- or lettuce-rotated conventional soils. The current highyielding strawberry cultivars used in California were selected for production under fumigated soils (19). Because these cultivars perform differently in nonfumigated conventional fields (22), yield differences from these cultivars may be exaggerated under nonfumigated conventional or organic production (28). However in 2002, strawberry yield was not significantly different in fumigated soils compared to that in broccoli-rotated conventional soils despite higher inoculum densities in the latter, probably because of inefficient fumigation in fumigated plots. Across treatments, yields were lower in 2002 compared to 2001, likely due in part to the change in cultivars planted.

Xiao et al. (45) outlined criteria for assessing rotation crops for effectiveness on persistent pathogens such as $V$. dahliae. The crop should (i) result in a reduction of microsclerotia in soil and a concomitant reduction of wilt in the susceptible crop, (ii) be compatible with current production practices, and (iii) result in grower acceptance of the crop for rotation. Broccoli meets these criteria; therefore, crop rotation with broccoli and its postharvest amendment into the soil continues to show promise as an additional tool in managing Verticillium wilt on susceptible hosts such as strawberry grown in succession with broccoli.

\section{ACKNOWLEDGMENTS}

The funding provided by USDA-SARE and the California Department of Food and Agriculture Department of Pesticide Regulation is gratefully acknowledged. The California Strawberry Commission, Coastal Berries, and Golden Field Green- houses provided material support for this project. We are grateful to Frank Westerlund for suggestions throughout this study. We thank Stuart Yamamoto for managing the strawberry crops, C. Blackford, T. Price, M. E. Abarca, and M. Orozco for technical assistance, and Mark Bolda for discussions on strawberry plant nutrient data. We also thank the anonymous reviewers whose comments and suggestions have significantly improved the manuscript.

\section{LITERATURE CITED}

1. Ajwa, H. A., and Trout, T. 2004. Drip application of alternative fumigants to methyl bromide for strawberry production. HortScience 39:1707-1715.

2. Ajwa, H. A., Trout, T., Muller, J., Wilhelm, S., Nelson, S. D., Soppe, R., and Shatley, D. 2002. Application of alternative fumigants through drip irrigation systems. Phytopathology 92:1349-1355.

3. Beckman, C. H., and Roberts, E. M. 1995. On the nature and genetic basis for resistance and tolerance to fungal wilt diseases of plants. Adv. Bot. Res. 21:35-77.

4. Bhat, R. G., and Subbarao, K. V. 1999. Host range specificity in Verticillium dahliae. Phytopathology 89:1218-1225.

5. Blok, W. J., Lamers, J. G., Termorshuizen, A. J., and Bollen, G. J. 2000. Control of soilborne plant pathogens by incorporating fresh organic amendments followed by tarping. Phytopathology 90:253-259.

6. Butterfield, E. J., and DeVay, J. E. 1977. Reassessment of soil assays for Verticillium dahliae. Phytopathology 67:1073-1078.

7. California Strawberry Commission. 2006. California strawberry 2007 acreage survey. Published online.

8. Carpenter, J., Gianessi, L., and Lynch, L. 2000. The economic impact of the scheduled U.S. phaseout of methyl bromide. National Center for Food and Agricultural Policy, Washington, DC. February 2000.

9. Coelho, L., Chellemi, D. O., and Mitchell, D. J. 1999. Efficacy of solarization and cabbage amendment for the control of Phytophthora spp. in North Florida. Plant Dis. 83:293-299.

10. Cohen, M. F., Yamasaki, H., and Mazzola, M. 2005. Brassica napus seed meal soil amendment modifies microbial community structure, nitric oxide production and incidence of Rhizoctonia root rot. Soil Biol. Biochem. 37:1215-1227.

11. De Cal, A., Martinez-Treceňo, A., LopezAranda, J. M., and Melgarejo, P. 2004. Chemical alternatives to methyl bromide in Spanish strawberry nurseries. Plant Dis. 88:210-214.

12. Duniway, J. M. 2002. Status of chemical alternatives to methyl bromide for pre-plant fumigation of soil. Phytopathology 92:1337-1343.

13. Duniway, J. M., Hao, J. J., Dopkins, D. M., Ajwa, H., and Browne, G. T. 2000. Some chemical, biological, and cultural alternatives to methyl bromide for strawberry. Abstr. 9. Annu. Int. Res. Conf. Methyl Bromide Alternatives Emissions Reductions. Orlando, FL.

14. Gamliel, A., and Stapleton, J. J. 1993. Characterization of antifungal volatile compounds evolved from solarized soil amended with cabbage residues. Phytopathology 83:899-905.

15. Harris, D. C., and Yang, J. R. 1996. The relationship between the amount of Verticillium dahliae in soil and the incidence of strawberry wilt as a basis for disease risk prediction. Plant Pathol. 45:106-114.

16. Kabir, Z., Bhat, R. G., and Subbarao, K. V. 2004. Comparison of media for recovery of Verticillium dahliae from soil. Plant Dis. 88:49-55.

17. Kabir, Z., Fennimore, S. A., Duniway, J. M., Martin, F. N., Browne, G. T., Winterbottom, C. Q., Ajwa, H. A., Westerdahl, B. B., Goodhue, R. E., and Haar, M. J. 2005. Alternatives to methyl bromide for strawberry runner plant production. HortScience 40:1709-1715.

18. Kuehl, R. O. 2000. Design of Experiments: Statistical Principles of Research and Design Analysis. 2nd ed. Duxbury Press, Pacific Grove, CA.

19. Larson, K. D., and Shaw, D. V. 1995. Relative performance of strawberry genotypes on fumigated and nonfumigated soils. J. Am. Soc. Hortic. Sci. 120:274-277.

20. Martin, F. N. 1999. Strawberry root rot and the recovery of Pythium and Rhizoctonia spp. Pages 6-1 to 6-3 in: Proc. Annu. Int. Res. Conf. Methyl Bromide Alternatives Emissions. San Diego, CA.

21. Martin, F. N. 2000. Rhizoctonia spp. recovered from strawberry roots in central coastal California. Phytopathology 90:345-353.

22. Martin, F. N. 2001. Management of pathogens associated with black root rot of strawberry. Pages 6-1 to 6-4 in: Proc. Annu. Int. Res. Conf. Methyl Bromide Alternatives Emissions. San Diego, CA.

23. National Agricultural Statistics Service. 2007. Vegetable 2006 Summary. Agricultural Statistics Board, NASS, U.S. Dep. Agric., Washington, DC.

24. Njoroge, S. M. C., Riley, M. B., and Keinath, A. P. 2008. Effect of incorporation of Brassica spp. residues on population densities of soilborne microorganisms and on damping-off and Fusarium wilt of watermelon. Plant Dis. 92:287-294.

25. Ochiai, N., Powelson, M. L., Dick, R. P., and Crowe, F. J. 2007. Effects of green manure type and amendment rate on Verticillium wilt severity and yield of Russet Burbank potato. Plant Dis. 91:400-406.

26. Paulus, A. L. 1990. Fungal diseases of strawberry. HortScience 25:885-889.

27. Rosado-May, F. J., Werner, M. R., Gliessman, S. R., and Webb, R. 1994. Incidence of strawberry root fungi in conventional and organic production systems. Appl. Soil Ecol. 1:261 267.

28. Schneider, S. M., Rosskopf, E. N., Leesch, J. G., Chellemi, D. O., Bull, C. T., and Mazzola, M. 2003. United States Department of Agriculture-Agricultural Research Service. Research on alternatives to methyl bromide Pre-plant and post-harvest. Pest Manag. Sci. 59:814-826.

29. Shetty, K. G., Subbarao, K. V., Huisman, O. C., and Hubbard, J. C. 2000. Mechanism of broccoli-mediated Verticillium wilt reduction in cauliflower. Phytopathology 90:305-310.

30. Smolinska, U. 2000. Survival of Sclerotium cepivorum sclerotia and Fusarium oxysporum chlamydospores in soil amended with cruciferous residues. J. Phytopathol. 148:343-349.

31. Subbarao, K. V. 2002. Biology and epidemiology of Verticillium wilt of lettuce. Pages 154 161 in: Annual Report of the California Lettuce Research Board for April 1, 2001 through March 31, 2002. California Lettuce Research Board, Salinas, CA

32. Subbarao, K. V., and Hubbard, J. C. 1996. Interactive effects of broccoli residue and temperature on Verticillium dahliae microsclerotia in soil and on wilt in cauliflower. Phytopathology 86:1303-1310.

33. Subbarao, K. V., Hubbard, J. C., Greathead, A S., and Spencer, G. A. 1997. Verticillium wilt Pages 26-27 in: Compendium of Lettuce Diseases. R. M. Davis, K. V. Subbarao, R. N. Raid, and E. A. Kurtz, eds. American Phytopathological Society, St Paul, MN.

34. Subbarao, K. V., Hubbard, J. C., and Koike, S T. 1999. Evaluation of broccoli residue incorporation into field soil for Verticillium wilt control in cauliflower. Plant Dis. 83:124-129.

35. Subbarao, K. V., Kabir, Z., Martin, F. N., and Koike, S. T. 2007. Management of soilborne diseases in strawberry using vegetable rota- 
tions. Plant Dis. 91:964-972.

36. Thomas, H. E. 1931. Verticilliosis of strawberries. Phytopathology 21:996.

37. U.S. Dep. Agric. Economic Research Service. 2000. Economic implications of the methyl bromide phaseout. Agric. Inf. Bull. No. 756.

38. Vallad, G. E., Qin, Q.-M., Grube, R., Hayes, R. J., and Subbarao, K. V. 2006. Characterization of race-specific interactions among isolates of Verticillium dahliae pathogenic on lettuce. Phytopathology 96:1380-1387.

39. Van Bruggen, A. H. C., and Termorshuizen, A. J. 2003. Integrated approaches to root disease management in organic farming systems. Aus- tralas. Plant Pathol. 32:141-156.

40. Wilhelm, S. 1955. Longevity of the Verticillium wilt fungus in the laboratory and field. Phytopathology 45:180-181.

41. Wilhelm, S. 1955. Verticillium wilt of the strawberry with special reference to resistance. Phytopathology 45:387-391.

42. Wilhelm, S. 1998. Verticillium wilt. Pages 5152 in: Compendium of Strawberry Diseases. J. L. Maas, ed. American Phytopathological Society, St Paul, MN.

43. Wilhelm, S., and Koch, E. C. 1956. Verticillium wilt controlled. Calif. Agric. 10:3-14.

44. Wing, K. B., Pritts, M. P., and Wilcox, W. F.
1994. Strawberry black root rot: A review. Adv. Strawberry Res. 13:13-19.

45. Xiao, C. L., Subbarao, K. V., Schulbach, K. F., and Koike, S. T. 1998. Effects of crop rotation and irrigation on Verticillium dahliae microsclerotia in soil and wilt in cauliflower. Phytopathology 88:1046-1055.

46. Zasada, I. A., Ferris, H., Elmore, C. L., Roncoroni, J. A., MacDonald, J. D., Bolkan, L. R., and Yakabe, L. E. 2003. Field application of brassicaceous amendments for control of soilborne pests and pathogens. Online. Plant Health Progress doi:10.1094/PHP-2003-112001-RS. 